Article

\title{
Preparation and Characterization of Self-Dispersing Phthalocyanine Blue 15:4 Pigment for Dyeing of Wool Textiles
}

\author{
Lun Nie ${ }^{\circledR}$, Guangtao Chang * and Ruoxin $\mathrm{Li}^{*}$ \\ College of Textile and Clothing Engineering, Soochow University, 199 Renai Road, Suzhou 215123, China; \\ 20184215035@stu.suda.edu.cn \\ * Correspondence: changgt@suda.edu.cn (G.C.); liruoxin@suda.edu.cn (R.L.)
}

Received: 3 July 2020; Accepted: 26 July 2020; Published: 29 July 2020

\begin{abstract}
A self-dispersing pigment was produced by a diazonium coupling reaction; the pigment reacted with aromatic diazonium salts which were generated by the reaction of $p$-aminobenzene sulfonic acid and sodium nitrite. The surface of the pigment particles was negatively charged due to sulfonic acid groups on the pigment surface. The pigment particle size and zeta potential were, respectively, $134.5 \mathrm{~nm}$ and $-45.4 \mathrm{mV}$ at neutral $\mathrm{pH}$. The wool surface was positively charged by adjusting the $\mathrm{pH}$; then the anionic self-dispersing pigment dyed the cationic wool. The results show that self-dispersing pigment can adhere well without a binder, and that the $K / S$ value is closely related to $\mathrm{pH}$, dyeing time, and the amount of pigment. The color fastness of the wool was good and the light fastness of the wool was grade 5, which is better than acid dyes. Self-dispersing pigments are potential candidates for dyeing high-weather-resistance textiles.
\end{abstract}

Keywords: pigment; self-dispersing; diazotization; dyeing; wool

\section{Introduction}

Traditionally, wool colorants are usually acid dyes, most of which contain sulfonate groups and are soluble in water [1-3]. Wool is mainly composed of protein, and has many carboxyl and amino groups. The isoelectric point of wool is about 4.2 to 4.8 . The wool surface will remain neutral when the $\mathrm{pH}$ is at isoelectric point. When the $\mathrm{pH}$ is lower than the isoelectric point, the amino groups on the wool surface are protonated and the wool surface becomes positive. When the $\mathrm{pH}$ is higher than the isoelectric point, the carboxyl groups on the wool surface are ionized and the wool surface is negatively charged. Acid dyes bind to wool fabrics by ionic bonds under acidic conditions [4-7]. Dyeing wool fabrics is a solution-based process that consumes an excessive amount of water and energy, and pollutes the environment [8-13]. Azo dyes in acid dyes are banned because of the risk of carcinogenesis [14,15]. In recent years, new colorants and dyeing methods have been developed [16,17].

Pigments have strong coloring power, bright color, complete color spectrum, acid/alkali resistance, good weather resistance, and are widely used in textile, paint, ink, plastic, rubber, and other industries [18-24]. Pigments are widely used in textile printing and coating dyeing because they are suitable for coloring different fibers and because they are eco-friendly. Pigment dyeing connects the pigment with fabric mostly by latex binders [25-27]. The fabric dyeing performance obviously depends on the quality of pigment dispersion, mainly the degree of dispersion and stability [28,29]. In recent years, the development of pigment products with high dispersion and stability has been the subject of a number of studies mainly involved in treating pigment with dispersant to reduce particle size [30-32]; for example, superfine pigments with an average particle size of 100-500 nm. Fabrics dyed with pigments having smaller particle size can achieve higher color intensity and 
soft-touch performance [33]. For example, Wang researched the dyeing of wool, acrylic, and other fabrics with ultra-fine pigments [34,35]. In addition, $\mathrm{Xu}$ has made good progress in the research of electrochemical dyeing technology for pigments [36].

In recent years, applying pigment to fabric dyeing in a water bath has been a hot research topic $[37,38]$. Water-based self-dispersing pigment is produced by surfaces modified with water-soluble groups [39-42]. The particle size of water-based self-dispersing pigment is smaller than that of superfine pigment, and can reach nanometer scale [43]. Dyes are easier to use because they do not need to be treated with dispersants. High-performance, water-based, self-dispersing pigments for dyeing fabrics have the advantage of good weather resistance, high fastness, softness and comfort, simple process, less waste water, and environmental safety. In 1996, Cabot Company applied water-based self-dispersing pigments modified by sulfonic acid diazotization to the inkjet industry [44]. In 2014, Stanovich treated the pigment with five-membered heterocycle diazo to produce a pigment with smaller particle size and better dispersion [45]. At present, there are few research groups, and a small number of innovative technologies on water-based self-dispersing pigments are under investigation.

Here we first studied fabric dyeing with self-dispersed pigments without binder, and compared them with acid dyes. The phthalein cyanine pigment was grafted with a hydrophilic sulfonic group, and the pigment surface was modified with negative charges. Water-based self-dispersing pigment was stabilized by electrostatic repulsion, and reaction impurities were removed by dialysis. We researched the effects of wool fabric dyeing with different dye bath $\mathrm{pH}$, dyeing times, and pigment dosage on dyeing absorbance, $K / S$ value, and color fastness. We compared the differences of dyeing fastness and coloring agent distribution between water-based self-dispersing pigment and acid dye, and found there are some merits in the self-dispersing pigment dyeing method, detailed in the following sections.

\section{Materials and Methods}

\subsection{Materials}

Wool fabric (plain weave, $125 \mathrm{~g} / \mathrm{m}^{2}$ ) was supplied by Shanghai Textile Industry Institute of Technical Supervision, Shanghai, China. $p$-Aminobenzene sulfonic acid was supplied by Shanghai Macklin Biochemical Ltd., Shanghai, China. Sodium nitrite was analytically pure and obtained from China Sun Specialty Products Company, Changshu, China. Pigment Blue 15:4 (7101F) was supplied by BASF. Acid Blue 93 was supplied by Shandong Usolf Chemical Technology Co., Ltd., Linyi, China. Hydrochloric acid (analytically pure) was obtained from China Sun Specialty Products Company, Changshu, China. Citric acid and disodium hydrogen phosphate were analytically pure and obtained from Sinopharm Chemical Reagent Co., Ltd., Shanghai, China.

\subsection{Preparation of Self-Dispersing Pigment}

First, $260 \mathrm{~g}$ water and $6.76 \mathrm{~g} p$-aminobenzene sulfonic acid were added to the mill, the mixture was dispersed for $5 \mathrm{~min}$ with 2000 revolutions per minute (RPM). Then, $0.3 \mathrm{~g}$ hydrochloric acid was added to adjust the solution $\mathrm{pH}$ to below 2 , and $20 \mathrm{~g}$ water-solution with $2.73 \mathrm{~g}$ sodium nitrite was added to the mixture. Subsequently, $30 \mathrm{~g}$ Pigment Blue was added. The mixture was dispersed for $20 \mathrm{~min}$ with $4000 \mathrm{RPM}$ at $20^{\circ} \mathrm{C}$. Next, $1200 \mathrm{~g}$ of zirconium bead was added to the mill to grind for $1 \mathrm{~h}$. The reaction scheme is shown in Figure 1. Lastly, the impurity was removed by dialysis over 3 days, and $2 \%$ aqueous self-dispersing pigment was obtained. 


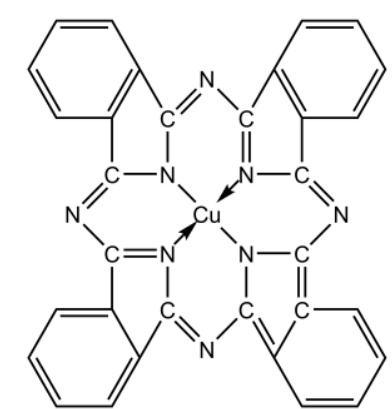

a<smiles>[Y19]OS(=O)(=O)c1ccc(N=C2C=CC(=C(c3ccc(Nc4ccc(S(=O)(=O)O)cc4)cc3)c3ccc(Nc4ccc(S(=O)(=O)O)cc4)cc3)C=C2)cc1</smiles>

$\mathrm{C}$

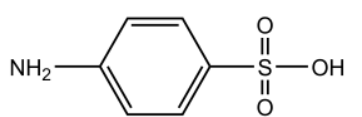

$\mathrm{b}$
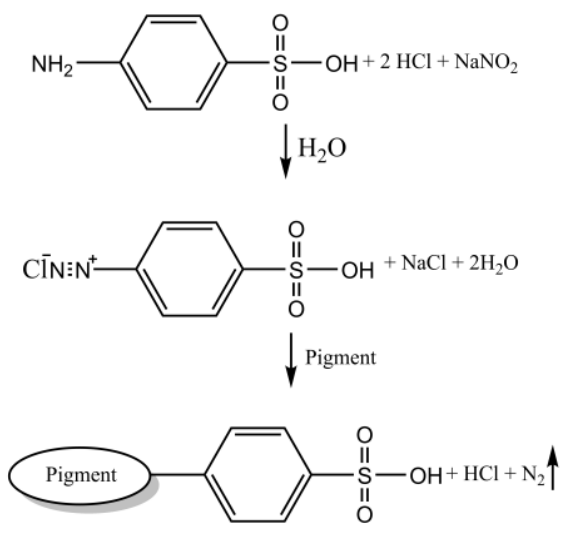

d

Figure 1. Chemical structure of (a) Pigment Blue 15:4; (b) p-aminobenzene sulfonic acid; (c) Acid Blue 93; and $(\mathbf{d})$ reaction scheme.

\subsection{Dyeing Procedure}

Wool fiber dyed with water-based self-dispersing pigments was treated at a liquor ratio of 1:50; the method is shown in Figure 2. As for dyeing with Acid Blue 93, samples were dyed using dyes instead of pigment under the same heating process shown in Figure 2. The $\mathrm{pH}$ was adjusted by buffer solution composed of $\mathrm{Na}_{2} \mathrm{HPO}_{4}$ and citric acid.

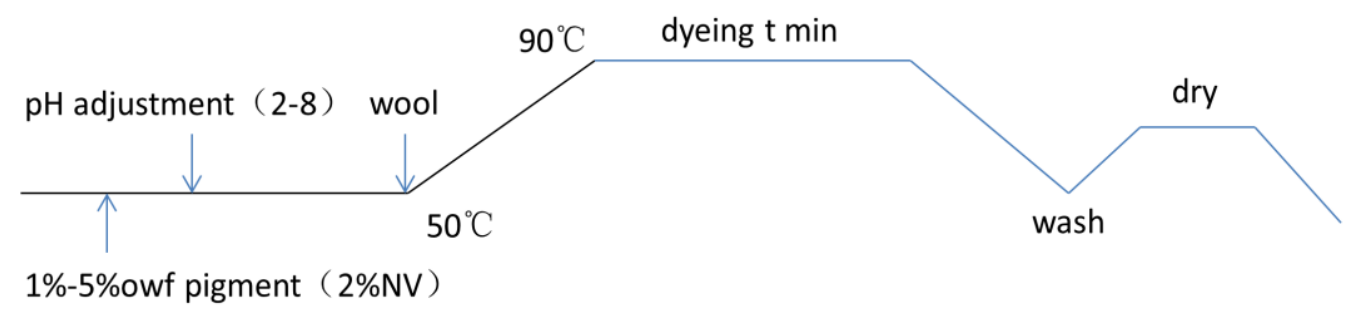

Figure 2. Dyeing process for wool with self-dispersing pigment.

\subsection{Testing and Measurements}

\subsubsection{Particle Size, PDI, and Zeta Potential}

The particle diameter, and PDI, and the zeta potential of pigment dispersions were determined by dynamic light scattering using a Zetasizer Nano ZS Nano-Zeta potential analyzer (Malvern Panalytical Co., Malvern, UK). The dispersions were diluted before measurement. 


\subsubsection{Absorption of Pigment and Pigment Uptake}

The absorbance was measured at a selected time $t$ on a SPECORD S600 spectrophotometer (Analytik Jena AG, Jena, Germany) at the wavelength of maximum absorption $(619 \mathrm{~nm})$ of the pigment. The pigment uptake was calculated according to the following equation:

$$
E_{t}=\left(1-D / D_{0}\right) \times 100 \%
$$

where $E_{t}$ is pigment uptake at time $t, D$ is the absorbance of the dye bath at time $t$, and $D_{0}$ is the absorbance of the original dye bath.

\subsubsection{X-ray Photoelectron Spectroscopy (XPS) Measurements}

XPS measurements were taken in a Thermo Kalpha (Thermo Fisher Scientific Inc., Waltham, MA, USA) using a monochromatic $\mathrm{Al} \mathrm{K} \alpha \mathrm{X}$-ray source to analyze the compositions of samples.

\subsubsection{Color Strength}

The $K / S$ values indicate the depth of shade reflected from the dyed fabric surface. $K / S=(1-$ $\left.R^{2}\right) / 2 R . R$ is the reflectance of the dyed fabric at the maximum absorption wavelength, and $K / S$ is the ratio of the absorption coefficient $(K)$ and the scattering coefficient $(S)$. The larger the $K / S$ value, the darker the color-that is, the higher the concentration of colored substances, the smaller the K/S value and the lighter the color. The measurement was carried out using a Hunterlab Ultrascan PRO reflectance spectrophotometer (HunterLab. Co., Ltd, Reston, VA, USA) under illuminant D65 using the $10^{\circ}$ standard observer. Color strength $(K / S)$ was calculated using the Kubelka-Munk equation.

\subsubsection{Rubbing Fastness}

To evaluate the rubbing fastness of dyed wool fabrics, samples were tested by a Y571B rubbing fastness tester (Nantong Hongda Experiment Instruments Co., Ltd., Nantong, China) using both dry and wet processes. The grade of rubbing fastness was determined according to the standard ISO 105-X12:2001.

\subsubsection{Light Fastness}

Light fastness was analyzed by exposing the dyed wool yarns for $40 \mathrm{~h}$ in a light fastness tester ATLAS-150S (ATLAS Co., Ltd., Essen, Germany). Light fastness was determined according to the standard ISO 105-B02:2000.

\subsubsection{Dye Permeability}

An SEM S-4800 (Hitachi, Tokyo, Japan) was used to observe the dyeing and morphology of the fabric at an acceleration voltage of $3 \mathrm{kV}$.

\section{Results and Discussion}

\subsection{Particle Size, PDI, and Zeta Potential}

The particle size has an effect on the permeability, coating, and color fastness of the pigment. The polydispersity index (PDI) provides information about the width of particle size distribution and affects the saturation of colored fabrics. Zeta potential influences the stability of pigment dispersion. Table 1 shows the results of water-based self-dispersing pigment modified by $p$-aminobenzene sulfonic acid. Here we combined physical sand milling technology and chemical modification technology. We successfully prepared the water-based self-dispersing nanoparticles at a size of $134.5 \mathrm{~nm}$, which is significantly smaller than the traditional dispersing particle size of 0.5-1.5 um [34]. Data are summarized in Table 1. 
Table 1. Particle size, polydispersity index (PDI), and zeta potential of the modified pigment.

\begin{tabular}{ccc}
\hline Particle Size $(\mathrm{nm})$ & PDI & Zeta Potential $(\mathrm{mV})$ \\
\hline 134.5 & 0.216 & -45.4 \\
\hline
\end{tabular}

The PDI of 0.216 shows that the pigment was uniform enough for dyeing. The self-dispersing pigment presented a zeta potential of $-45.4 \mathrm{mV}$ at neutral $\mathrm{pH}$, indicating that pigment particles carried plenty of negative charge. Through a diazotization reaction, the hydrophilic sulfonic acid group was grafted to the pigment surface, so that the pigment surface had a large amount of negative charge. Electrostatic repulsion had the effect of forming a stable, highly dispersed pigment in the water. After the removal of impurities by dialysis, dyeing pastes were obtained.

\subsection{UV-Vis Absorption}

We knew that if the color of the modified pigment changed greatly, it would cause a lot of trouble for later application, modification, and development of other pigments. The objective was for the color to remain the same, and to achieve the maximum retention of the optical properties before and after modification. Therefore, in order to verify whether the color of the modified pigment was changed, an absorption vs. wavelength curve was obtained with a UV-visible spectrophotometer, as shown in Figure 3. It can be seen from the figure that the curve was basically the same, and that the modified pigment had the same color as the unmodified pigment.

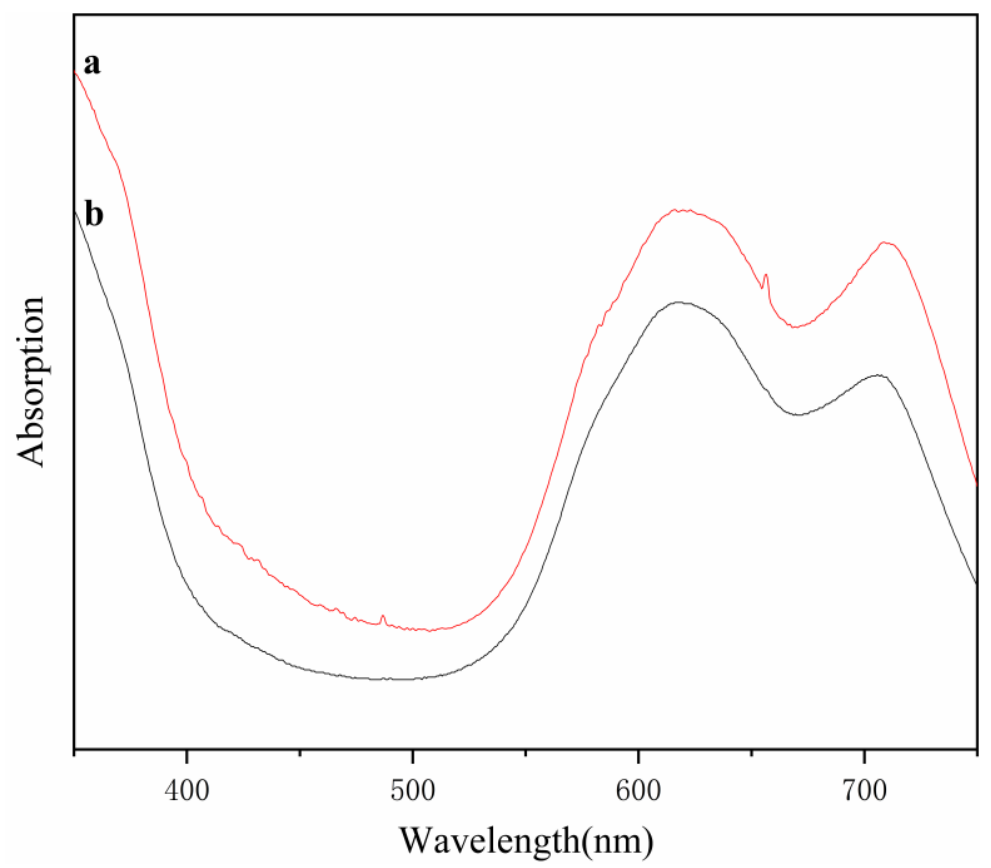

Figure 3. Absorption of visible light of unmodified pigments (a) and modified pigments (b).

\subsection{XPS}

The prepared water-based self-dispersing pigment (modified pigment) and unmodified pigment were dried to a powder at $80^{\circ} \mathrm{C}$ for one hour, and samples were measured using a monochromatic $\mathrm{Al}$ $\mathrm{K} \alpha \mathrm{X}$-ray source to analyze the compositions. Compared with the physical absorption of dispersants used in the traditional method of dispersing pigments, the modification method in this paper was a chemical modification with the addition of a sulfonic acid group, so the chemical element composition of pigments was bound to change. Changes to oxygen and sulfur content have important characterization significance. As can be seen from Table 2, the content of oxygen increased from 3.07\% to $10.19 \%$, 
and the content of sulfur increased from $0.21 \%$ to $1.74 \%$. The increase of oxygen and sulfur showed that the sulfonic acid group reacted to the surface of the pigment. Combined with the above comprehensive verification, it can be concluded that the water-based self-dispersing pigments were successfully prepared.

Table 2. Element amount of unmodified pigments (UP) and modified pigments (MP).

\begin{tabular}{ccccc}
\hline Sample & $\mathbf{C ~ ( \% )}$ & $\mathbf{N ~ ( \% )}$ & $\mathbf{O ~ ( \% )}$ & $\mathbf{S ~ ( \% )}$ \\
\hline UP & 80.09 & 16.63 & 3.07 & 0.21 \\
MP & 75.61 & 12.45 & 10.19 & 1.74 \\
\hline
\end{tabular}

\subsection{Effect of Dyebath $\mathrm{pH}$ on Uptake}

The most critical factor influencing wool dyeing is $\mathrm{pH}$, because wool has an isoelectric point [34]. This is the key variable regarding exploration of the impact of $\mathrm{pH}$ on wool dyeing, and this article explores changes in $\mathrm{pH}$ from 2.5 to 8 , at a dyeing time of $60 \mathrm{~min}$, and with $2 \%$ owf modified pigment. Figure 4 shows that with the increase of $\mathrm{pH}$, the uptake of pigments decreased. The highest uptake was $91.2 \%$ with $\mathrm{pH} 2.5$, so we can say that the rate of dyeing increased as $\mathrm{pH}$ decreased. Dyeing under the condition of acid or alkali will produce larger damage to fabric, so a $\mathrm{pH}$ of 2.5 should be chosen to reach a better result.

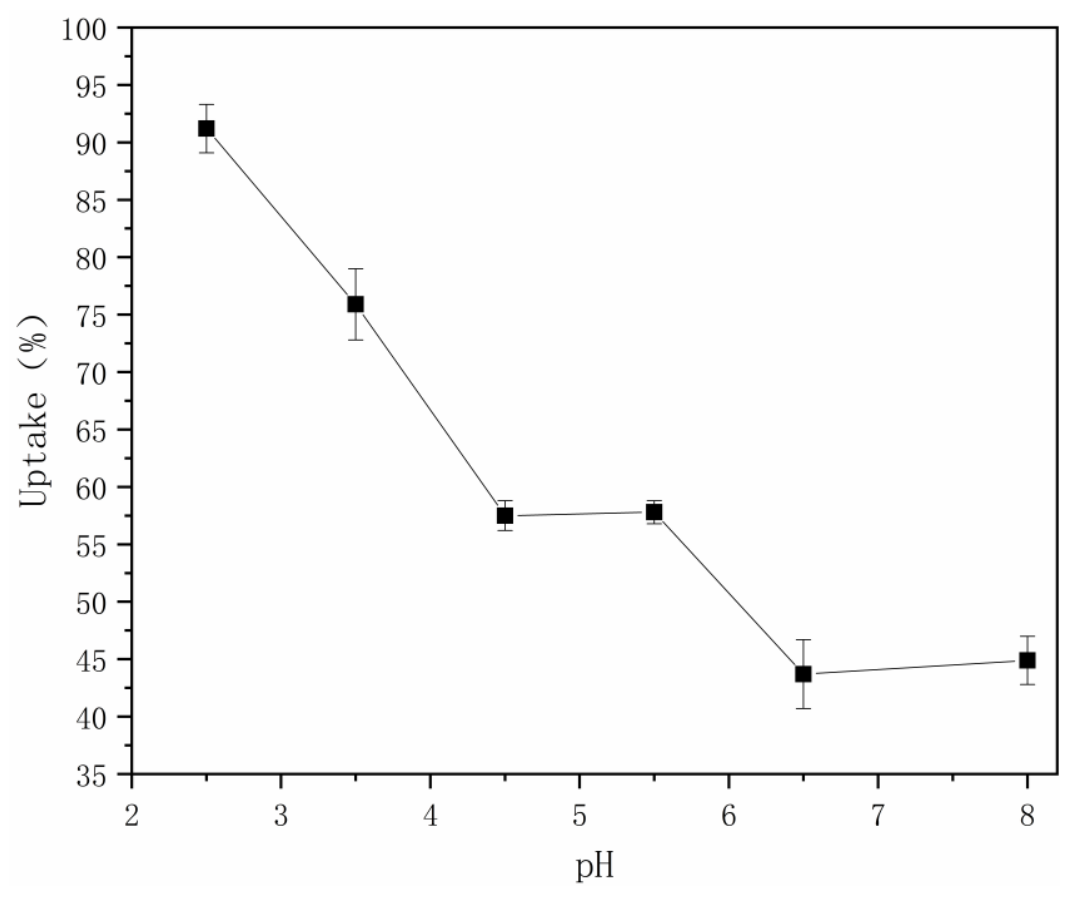

Figure 4. Effect of dyebath $\mathrm{pH}$ on uptake.

\subsection{Effect of Dyeing Time on Uptake}

Higher uptakes and shorter dyeing times have a great impact on actual production. If uptakes can reach $100 \%$ in a short period of time, the treatment of wastewater from dyeing and finishing processes will be greatly improved and will have a measurable impact on the goal of water conservation. Therefore, we studied the change of uptake over time at $\mathrm{pH} 2.5$ and with $2 \%$ owf modified pigment, as shown in Figure 5. We can see that the uptake increased with the increase of dyeing time. When the dyeing time was $100 \mathrm{~min}$, the dyeing rate reached $98 \%$, or close to $100 \%$. So, the dyeing method is feasible. 


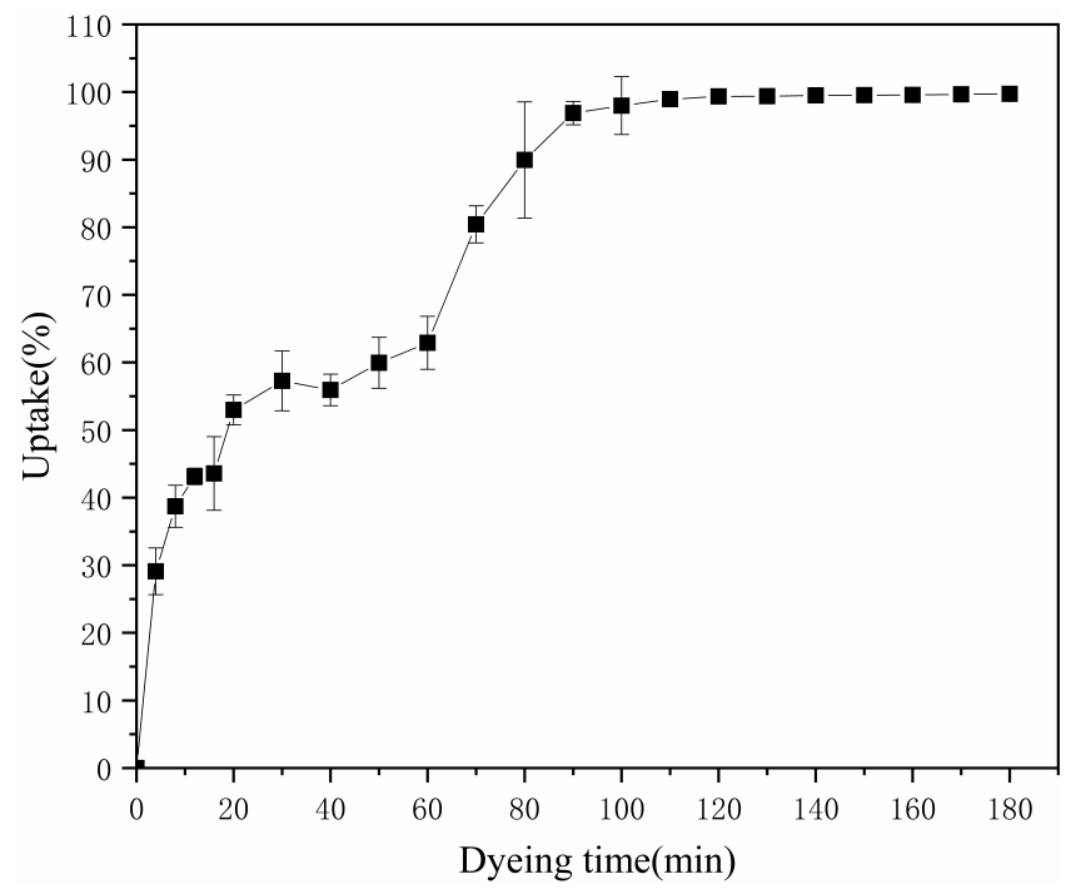

Figure 5. Effect of dyeing time on uptake of the self-dispersing pigments.

\subsection{Effect of Dyeing Time on K/S Value}

$K / S$ value is often used to indicate the apparent color depth of dyed fabrics. When the value is higher, the dyeing color is better. We studied the change of $K / S$ over time at $\mathrm{pH} 2.5$ and with $2 \%$ owf modified pigment. As shown in Figure 6, it can be seen that the $K / S$ value increased with the extension of dyeing time. At $80 \mathrm{~min}$, the $K / S$ value of the fabric reached 13.19, indicating that the fabric was deeply dyed [34-36]. Considering the influence of too-long dyeing times on production and processing, the dyeing time of $80 \mathrm{~min}$ was able to achieve a better effect.

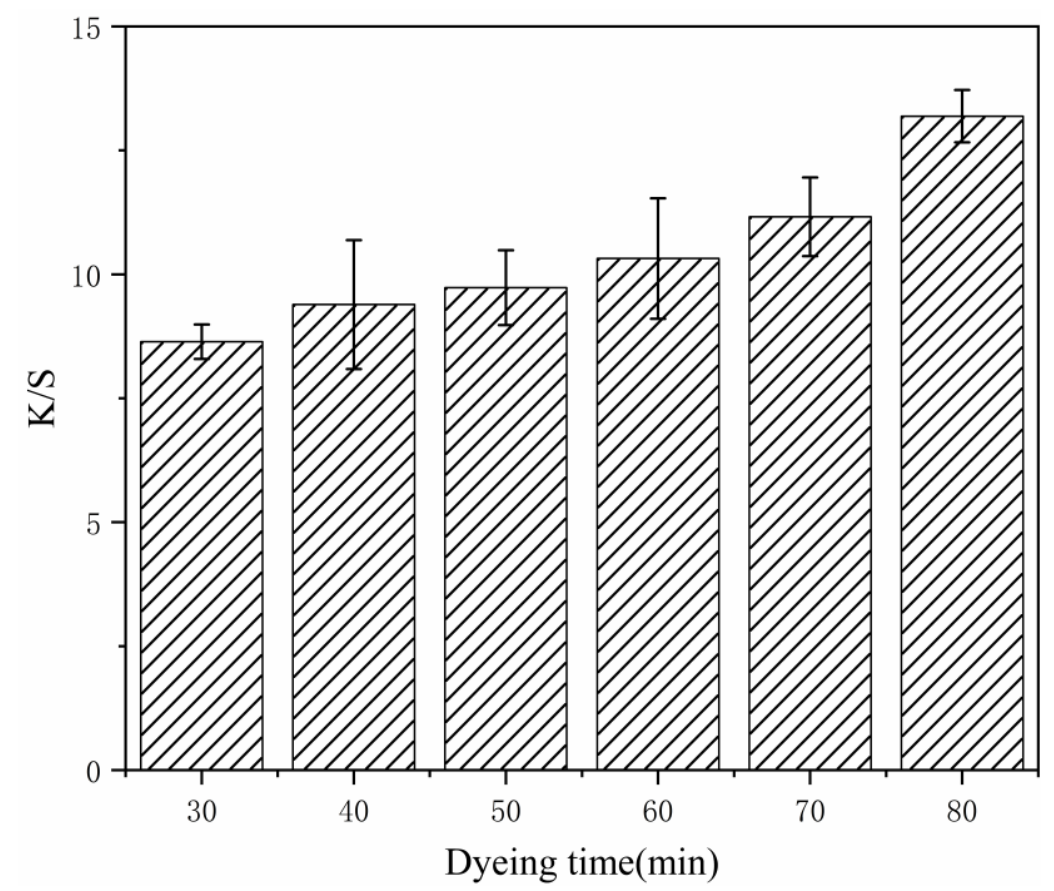

Figure 6. Effect of dyeing time on $K / S$ value. 


\subsection{Effect of Pigment Amount on K/S Value}

The amount of pigment can affect the contact probability between pigment and fabric, as well as the complete dyeing of fabric. Therefore, at pH 2.5 and a dyeing time $60 \mathrm{~min}$, we analyzed the change of $K / S$ value with the amount of pigment. As shown in Figure 7, the $K / S$ value was maximum at $1 \%$ owf. When the amount of pigment was increased, the $K / S$ decreased and did not have the expected effect. Considering the influence of dyeing fastness on color fading in later tests, the data from the experiment and the color depth of dyeing liquid after dyeing were used to comprehensively determine that the pigment dosage at $2 \%$ owf could achieve a better effect.

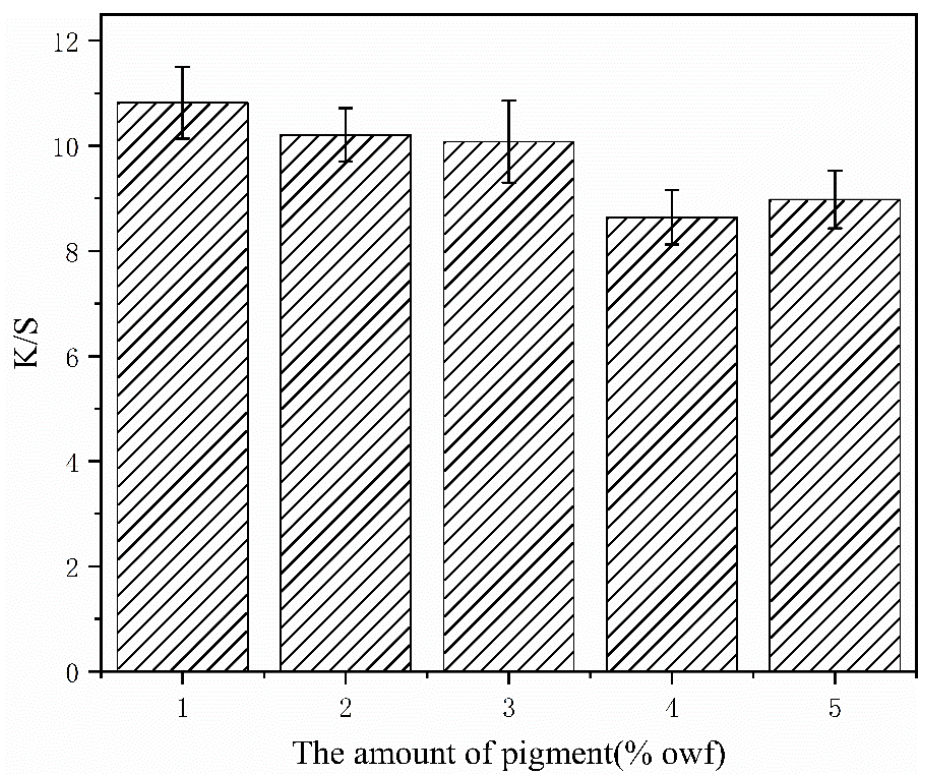

Figure 7. Effect of pigment amount on $K / S$ value.

\subsection{Comparison of Distribution on Dyed Fabric}

In order to compare the chromaticity distribution of modified pigment and dye on dyed wool yarn, the dyed fabric, with modified pigment and Acid Blue 93, was sliced and observed by SEM. The result is shown in Figure 8. The modified pigment was obviously present on the surface of the fiber, and there was a large number of concentrated large particles deposited on the fiber, indicating that the pigment could be properly dyed on the fiber [38]. The Acid Blue 93 dyeing fiber had no obvious large particle deposition on the surface, and the wool scale layer could also be clearly seen, indicating that more dye had entered into the fiber, so the permeability was better. The reason is that the particle size of the modified pigment was larger than the dye.
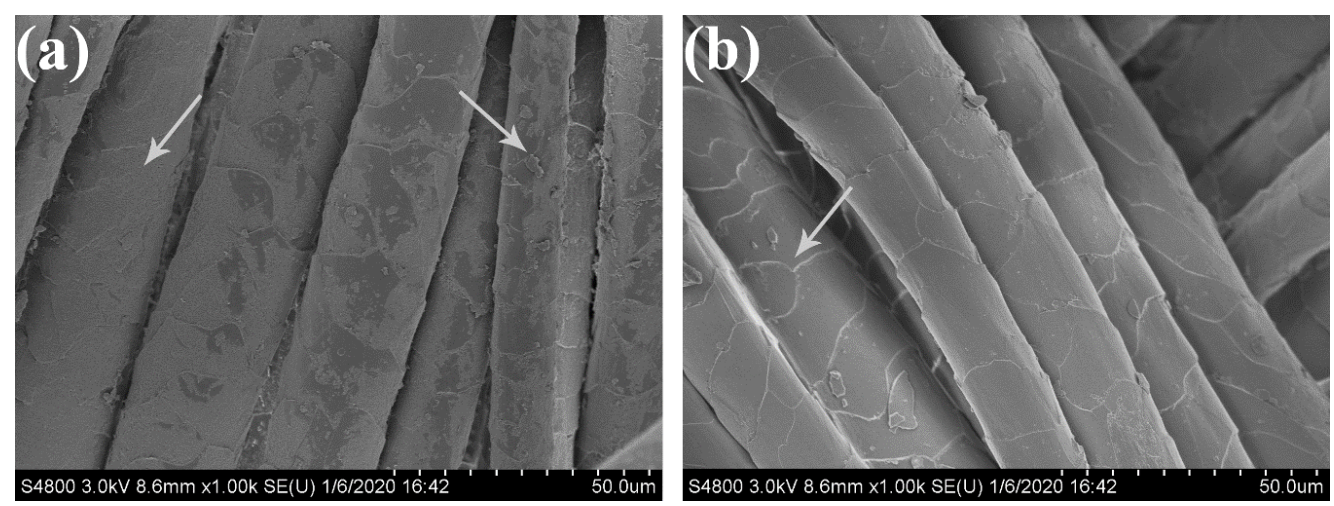

Figure 8. SEM of modified pigments (a) and the dye Acid Blue 93 (b). 


\subsection{Comparison of Fastness}

It can be seen from Figure 9 and Table 3 that the color of wool fabrics dyed by modified pigments showed little change, while the color of wool fabrics dyed by acid dyes showed great change. So, we can conclude that the color fastness of the modified-pigment-dyed fabric was better than that of the fabric dyed with the acid dye [34-36,38]. The chemical bond energy of pigments is high and the resistance to light is strong, which is the reason for the high light fastness. However, when dyes are chosen for colorants, the light damage to them is greater, and the fastness to light is even worse. The two colorants have no difference in rubbing fastness.
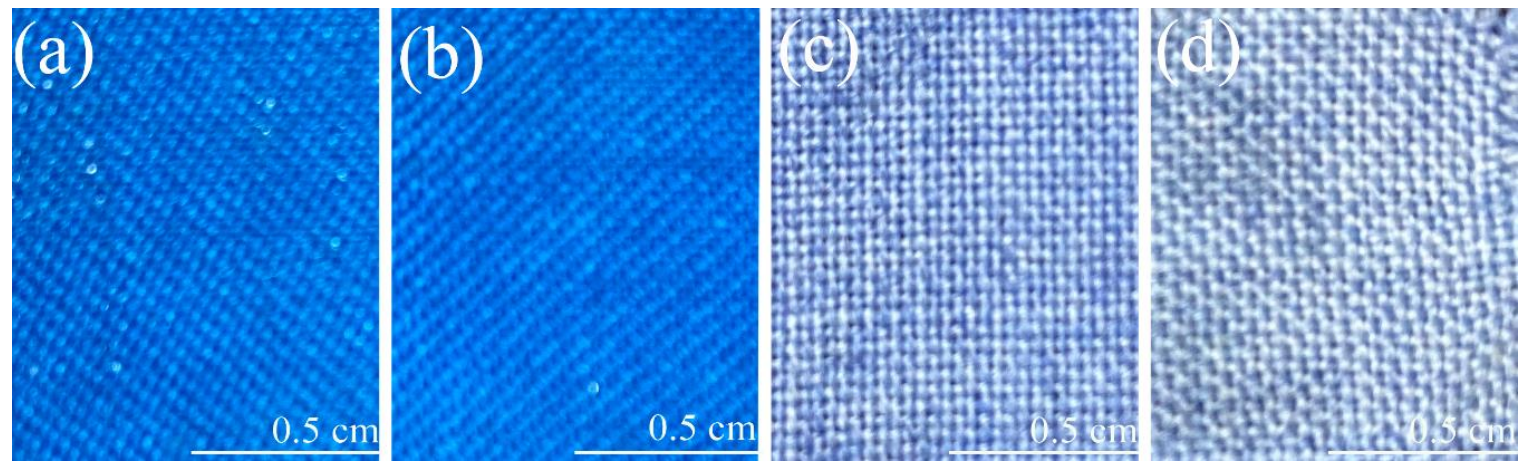

Figure 9. Fabric dyed with modified pigment without a light fastness test (a) and with a light fastness test (b); fabric dyed with acid dye without a light fastness test (c) and with a light fastness test (d).

Table 3. Comparison of the fastness of modified pigment (MP) and Acid Blue 93 Dye.

\begin{tabular}{cccc}
\hline Sample & Light Fastness & Dry Rubbing Fastness & Wet Rubbing Fastness \\
\hline MP & 5 & 3 & 3 \\
Dye & 3 & 3 & 3 \\
\hline
\end{tabular}

\section{Conclusions}

By physical grinding and chemical modification, the hydrophilic sulfonic acid group on $p$-aminobenzene sulfonic acid was successfully grafted through a diazotization reaction under the action of high-speed grinding, and a water-based self-dispersing pigment with a particle size of $134.5 \mathrm{~nm}$, a PDI of 0.216 , and a zeta potential $-45.4 \mathrm{mV}$ was successfully prepared. The uptake of dyed wool fabric reached $90 \%$ with a $\mathrm{pH}$ of 2.5 , a dyeing temperature of $90{ }^{\circ} \mathrm{C}$, a dyeing time of $80 \mathrm{~min}$, and a pigment dosage of $2 \%$ owf. The $K / S$ value reached 13.19 , resulting in a better dyeing effect. When the dyeing time was extended to $100 \mathrm{~min}$, the uptake reached $98 \%$, close to $100 \%$. At the same time, the evenness of dyeing was good and the weather resistance was excellent. Dry-rubbing fastness and wet-rubbing fastness were nearly the same compared to acid dyes used for dying textiles. The self-dispersed pigment dying method may be a useful tool for producing high-grade light-fast fabrics.

Author Contributions: Conceptualization, L.N. and R.L.; Funding acquisition, R.L. and G.C.; Investigation, L.N., R.L., and G.C.; Project administration, R.L. and G.C.; Supervision, R.L. and G.C.; Visualization, L.N.; Writing-original draft, L.N.; Writing-review and editing, R.L. and G.C. All authors have read and agreed to the published version of the manuscript.

Funding: This research was funded by the Research Funding of Soochow University (Q411500218) and Soochow University-Suzhou Central Asia Ink Co., Ltd. Co-innovation Center Co-Construction Agreement (P111500219).

Conflicts of Interest: The authors declare no conflict of interest.

\section{References}

1. Burkinshaw, S.M.; Kumar, N. The mordant dyeing of wool using tannic acid and $\mathrm{FeSO}_{4}$, Part 1: Initial findings. Dyes Pigment. 2009, 80, 53-60. [CrossRef] 
2. Fakin, D.; Ojstrsek, A.; Benkovic, S.C. The impact of corona modified fibres' chemical changes on wool dyeing. J. Mater. Process. Technol. 2009, 209, 584-589. [CrossRef]

3. Zhang, Y.Z.; Hou, W.F.; Tan, Y.P. Structure and dyeing properties of some anthraquinone violet acid dyes. Dyes Pigment. 1997, 34, 25-35. [CrossRef]

4. Wang, H.Y.; Wang, G.W.; Zheng, C.L.; Zhou, T.J.; Sun, J. Synthesis of acid dyes containing polyetheramine moieties and their low-temperature dyeing properties on wool fiber. J. Appl. Polym. Sci. 2018, 135, 9. [CrossRef]

5. Cai, Z.S.; Qiu, Y.P. Dyeing properties of wool fabrics treated with atmospheric pressure plasmas. J. Appl. Polym. Sci. 2008, 109, 1257-1261. [CrossRef]

6. Abdelrahman, M.S.; Nassar, S.H.; Mashaly, H.; Mahmoud, S.; Maamoun, D.; El-Sakhawy, M.; Khattab, T.A.; Kamel, S. Studies of Polylactic Acid and Metal Oxide Nanoparticles-Based Composites for Multifunctional Textile Prints. Coatings 2020, 10, 58. [CrossRef]

7. Assefi Pour, R.; He, J. Surface Functionalization of Wool via Microbial-Transglutaminase as Bio-Mordant to Improve Dyeability with Madder in the Presence of Alum. Coatings 2020, 10, 78. [CrossRef]

8. Shams-Nateri, A. Reusing wastewater of madder natural dye for wool dyeing. J. Clean. Prod. 2011, 19, 775-781. [CrossRef]

9. Ozturk, E.; Karaboyaci, M.; Yetis, U.; Yigit, N.O.; Kitis, M. Evaluation of Integrated Pollution Prevention Control in a textile fiber production and dyeing mill. J. Clean. Prod. 2015, 88, 116-124. [CrossRef]

10. Tigini, V.; Prigione, V.; Giansanti, P.; Mangiavillano, A.; Pannocchia, A.; Varese, G.C. Fungal Biosorption, an Innovative Treatment for the Decolourisation and Detoxification of Textile Effluents. Water 2010, 2, 550-565. [CrossRef]

11. Zhou, L.; Zhou, H.J. Evaluation of textile industry wastewater treatment and reuse in China. Desalin. Water Treat. 2019, 144, 330-338. [CrossRef]

12. Bisschops, I.; Spanjers, H. Literature review on textile wastewater characterisation. Environ. Technol. 2003, 24, 1399-1411. [CrossRef]

13. Liang, W.; Hu, H.Y.; Song, Y.D.; Wang, H.; Guo, Y.F. Effects of thiamine on treatment performance of textile wastewater. Desalination 2009, 242, 110-114. [CrossRef]

14. Wang, C.; Fang, K.; Ji, W. Superfine pigment dyeing of silk fabric by exhaust process. Fibers Polym. 2007, 8, 225-229. [CrossRef]

15. Hao, L.Y.; Cai, Y.Q.; Wang, R. Preparation of Ultrafine Pigment Dispersion and Investigation of its Adsorption Performance on Cationized Flax Substrate. Adsorpt. Sci. Technol. 2011, 29, 875-885. [CrossRef]

16. Ma, W.; Du, S.; Yan, S.; Yu, X.; Zhang, Z.; Zhang, S. Salt-Free Dyeing of Modified Cotton through Graft Polymerization with Highly Enhanced Dye Fixation and Good Strength Properties. Polymers 2020, 12, 462. [CrossRef]

17. Wang, M.; Wang, X.; Guo, C.; Zhao, T.; Li, W. A Feasible Method Applied to One-Bath Process of Wool/Acrylic Blended Fabrics with Novel Heterocyclic Reactive Dyes and Application Properties of Dyed Textiles. Polymers 2020, 12, 285. [CrossRef] [PubMed]

18. Sun, J.Z.; Wei, X.F.; Huang, P.Q.; Liu, Q.L. Preparation of the Plastic Water-Based Gravure Primary Ink with High Pigment. Adv. Mater. Res. 2011, 380, 15-19. [CrossRef]

19. Vega Gutierrez, S.M.; He, Y.; Cao, Y.; Stone, D.; Walsh, Z.; Malhotra, R.; Chen, H.-L.; Chang, C.-H.; Robinson, S.C. Feasibility and Surface Evaluation of the Pigment from Scytalidium cuboideum for Inkjet Printing on Textiles. Coatings 2019, 9, 266. [CrossRef]

20. Rocha, S.; Freitas, L., Jr.; Costa, C. Smart, Photocatalytic and Self-Cleaning Asphalt Mixtures: A Literature Review. Coatings 2019, 9, 696. [CrossRef]

21. Chiloeches, A.; Echeverría, C.; Fernández-García, M.; Muñoz-Bonilla, A. Influence of Polymer Composition and Substrate on the Performance of Bioinspired Coatings with Antibacterial Activity. Coatings 2019, 9, 733. [CrossRef]

22. Saleemi, S.; Naveed, T.; Riaz, T.; Memon, H.; Awan, J.A.; Siyal, M.I.; Xu, F.; Bae, J. Surface Functionalization of Cotton and PC Fabrics Using $\mathrm{SiO}_{2}$ and $\mathrm{ZnO}$ Nanoparticles for Durable Flame Retardant Properties. Coatings 2020, 10, 124. [CrossRef]

23. Rossi, S.; Russo, F.; Bouchakour Rahmani, L. Study of the Durability and Aesthetical Properties of Powder Coatings Admixed with Pearlescent Pigments. Coatings 2020, 10, 229. [CrossRef] 
24. Kasaw, E.; Haile, A.; Getnet, M. Conductive Coatings of Cotton Fabric Consisting of Carbonized Charcoal for E-Textile. Coatings 2020, 10, 579. [CrossRef]

25. Gorgieva, S.; Virant, N.; Ojstrsek, A. Complementary Assessment of Commercial Photoluminescent Pigments Printed on Cotton Fabric. Polymers 2019, 11, 1216. [CrossRef]

26. Hakeim, O.A.; Abdelghaffar, F.; Haroun, A.A. UV-curable hyperbranched polyester acrylate encapsulation of phthalocyanine pigments for high performance synthetic fabrics printing. Dyes Pigment. 2020, 177. [CrossRef]

27. Gao, D.; Feng, J.; Ma, J.; Lu, B.; Lin, J.; Zhang, J. Synthesis of cationic binder through surfactant-free emulsion polymerization for textile pigment applications. Prog. Org. Coat. 2014, 77, 1834-1840. [CrossRef]

28. El-Shishtawy, R.M.; Nassar, S.H. Cationic pretreatment of cotton fabric for anionic dye and pigment printing with better fastness properties. Color. Technol. 2002, 118, 115-120. [CrossRef]

29. Hakeim, O.A.; Abdou, L.A.W.; El-Gammal, M.S.; El-Naggar, A.M. An approach for vat color printing on cotton and polyester fabrics with electron beam irradiation curable formulations. Carbohydr. Polym. 2012, 87, 1467-1475. [CrossRef]

30. Fang, K.; Jiang, X.; Wang, C.; Wu, M.; Yan, Y. Properties of the nanoscale hydrophilic cationic pigment based on quaternary surfactant. J. Dispers. Sci. Technol. 2008, 29, 52-57. [CrossRef]

31. Cao, L.; Fei, X.; Zhao, H.; Huang, C. Preparation of phthalocyanine blue/rutile TiO2 composite pigment with a ball milling method and study on its NIR reflectivity. Dyes Pigment. 2020, 173. [CrossRef]

32. Zhang, B.L.; Zhang, Z.Z.; Fei, X.N.; Gu, Y.C.; Yu, L. Preparation and properties of CI Pigment Red 170 modified with silica fume. Pigment. Resin. Technol. 2016, 45, 141-148. [CrossRef]

33. Hao, L.; Wang, R.; Liu, J.; Liu, R. Ultrasound-assisted adsorption of anionic nanoscale pigment on cationised cotton fabrics. Carbohydr. Polym. 2012, 90, 1420-1427. [CrossRef]

34. Li, Y.; Ren, J.; Chen, S.; Fan, F.; Shen, Q.; Wang, C. Cationic Superfine Pigment Dyeing for Wool Using Exhaust Process by pH Adjustment. Fibers Polym. 2015, 16, 67-72. [CrossRef]

35. Wang, K.; Wang, C.; Wang, C. Acrylic yarns dyeing properties of cationic ultra-fine pigment modified by TDBAC. Colloids Surf. A 2013, 431, 114-119. [CrossRef]

36. Cao, G.; Lu, X.; Xu, W.; Wang, X. Electrochemical Pigment Coloring of Wool Fabrics. Fibers Polym. 2018, 19, 65-70. [CrossRef]

37. Li, M.; Zhang, L.; Qiu, M.; Zhang, Y.; Fu, S. Dyeing property of fluorescent pigment latex on cationic knitted cotton fabrics. Text. Res. J. 2019, 89, 422-433. [CrossRef]

38. Мa, T.; Cao, Y.; Chen, H. Synthesis and characterization of cationic carbon black pigment with quaternary ammonium groups and its dyeing properties for wool fabrics. Colloids Surf. A 2018, 549, 43-49. [CrossRef]

39. Eshkalak, S.K.; Khatibzadeh, M.; Kowsari, E.; Chinnappan, A.; Ramakrishna, S. A novel surface modification of copper (II) phthalocyanine with ionic liquids as electronic ink. Dyes Pigment. 2018, 154, 296-302. [CrossRef]

40. Eshkalak, S.K.; Khatibzadeh, M.; Kowsari, E.; Chinnappan, A.; Ramakrishna, S. Application of ionic liquids as charge control agents of pigments and preparation of microcapsules as electronic inks through electrospraying. Opt. Mater. 2018, 84, 73-81. [CrossRef]

41. Leelajariyakul, S.; Noguchi, H.; Kiatkamjornwong, S. Surface-modified and micro-encapsulated pigmented inks for ink jet printing on textile fabrics. Prog. Org. Coat. 2008, 62, 145-161. [CrossRef]

42. Li, D.; Sun, G. Coloration of textiles with self-dispersible carbon black nanoparticles. Dyes Pigment. 2007, 72, 144-149. [CrossRef]

43. Nagose, S.; Rose, E.; Joshi, A. Study on wetting and dispersion of the Pigment Yellow 110. Prog. Org. Coat. 2019, 133, 55-60. [CrossRef]

44. Yu, Y.; Gambale, R.J.; Amici, R.M. Process for Preparing Surface-Modified Pigments and Applications for Ink Jet Ink. Patent WO2000052102A1, 8 September 2000.

45. Shakhnovich, A.I. Modified Pigments. U.S. Patent 8,771,411B2, 8 July 2014.

(C) 2020 by the authors. Licensee MDPI, Basel, Switzerland. This article is an open access article distributed under the terms and conditions of the Creative Commons Attribution (CC BY) license (http://creativecommons.org/licenses/by/4.0/). 